\section{Hypertensive crisis after endoscopic ultrasound- guided fine-needle aspiration of the right adrenal gland}

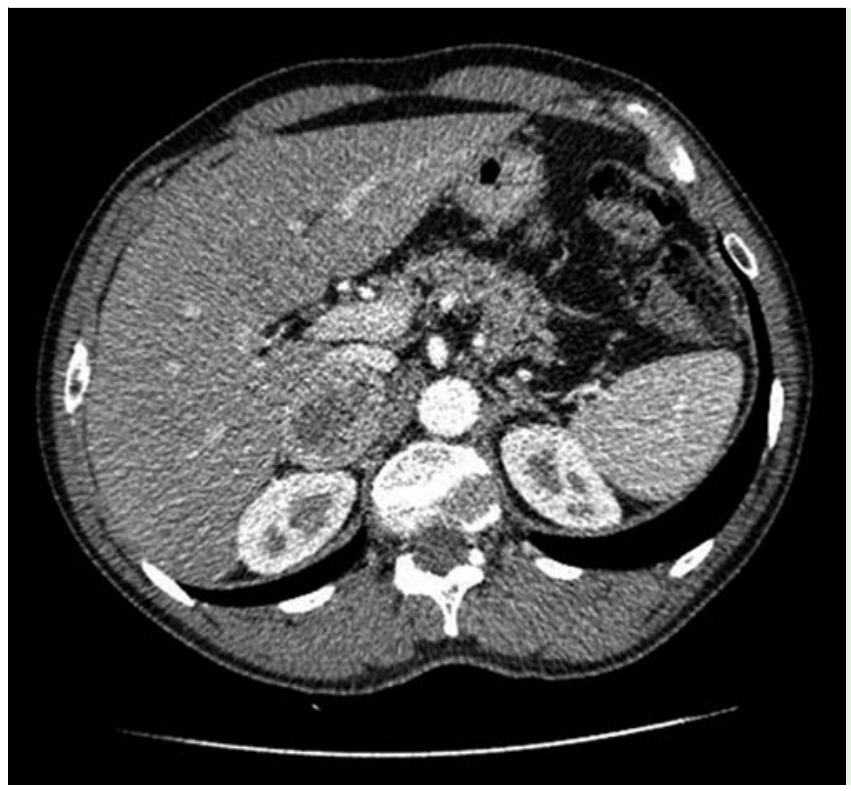

Fig. 1 In a 51-year-old man with suspected adrenal metastasis of lung cancer, computed tomography (CT) scan showed an enlarged right adrenal gland with a heterogeneous appearance.

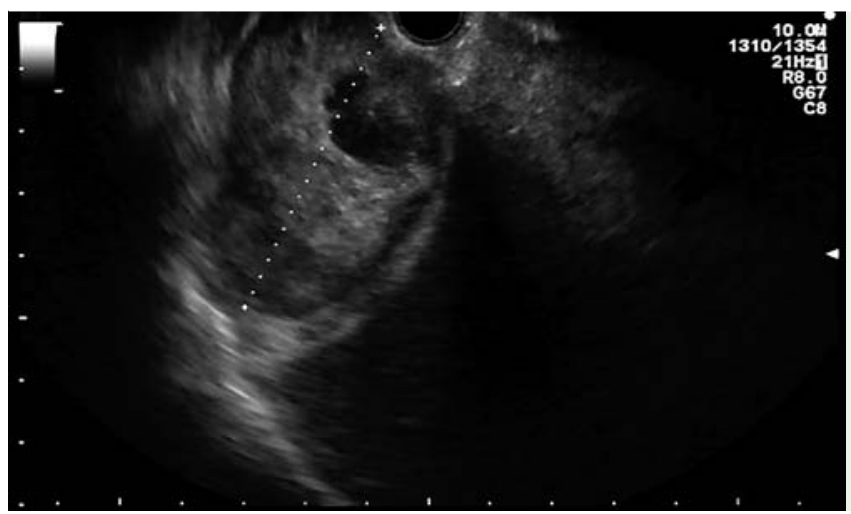

The patient was immediately admitted to the intensive care unit with a provisional diagnosis of hypertensive crisis and secondary acute decompensated heart failure, most likely due to puncture into a pheochromocytoma. Cytologic evaluation of the FNA specimen confirmed the diagnosis as it revealed irregularly arranged monomorphic cells with round nuclei, and positive staining for chromogranin $(\checkmark$ Fig.3a,b). After laparoscopic right-sided adrenalectomy for the pheochromocytoma, the patient slowly recovered, and was discharged home a few weeks later. Further pulmonological evaluation did not demonstrate lung cancer.

Depending on its capacity to release catecholamines to the systemic circulation, pheochromocytoma may evoke mild or nonspecific signs and symptoms, and as a consequence, up to $15 \%$ of tumors remain undiagnosed during life $[1,2]$. EUSguided FNA of adrenal pheochromocytomas without any complications has been described in small numbers in case series [3-5]. Accordingly, a recent American Society for Gastrointestinal Endoscopy guideline on adverse events associated with EUS-guided FNA does not describe the risk reported here [6]. Our case shows that EUS-guided puncture of pheochromocytoma may evoke an abrupt release of catecholamines, and subsequently, a lifethreatening hypertensive crisis, similar to the well-known risk of percutaneous biopsy [2]. Based on this case, we advise exclusion of (subclinical) pheochromocytoma before all EUS-guided punctures of adrenal lesions, by 24-h urine collection for metanephrines and catecholamines [7].

Endoscopy_UCTN_Code_CPL_1AL_2AF

Competing interests: None

\section{Annemarie C. de Vries, Jan-Werner Poley}

Department of Gastroenterology and Hepatology, Erasmus MC University Medical Center, Rotterdam, The Netherlands

\section{References}

1 Mannelli M, Lenders JW, Pacak K et al. Subclinical phaeochromocytoma. Best Pract Res Clin Endocrinol Metab 2012; 26: 507-515

2 Vanderveen KA, Thompson SM, Callstrom MR et al. Biopsy of pheochromocytomas and paragangliomas: potential for disaster. Surgery 2009; 146: $1158-1166$

3 Akdamar MK, Eltoum I, Eloubeidi MA. Retroperitoneal paraganglioma: EUS appearance 


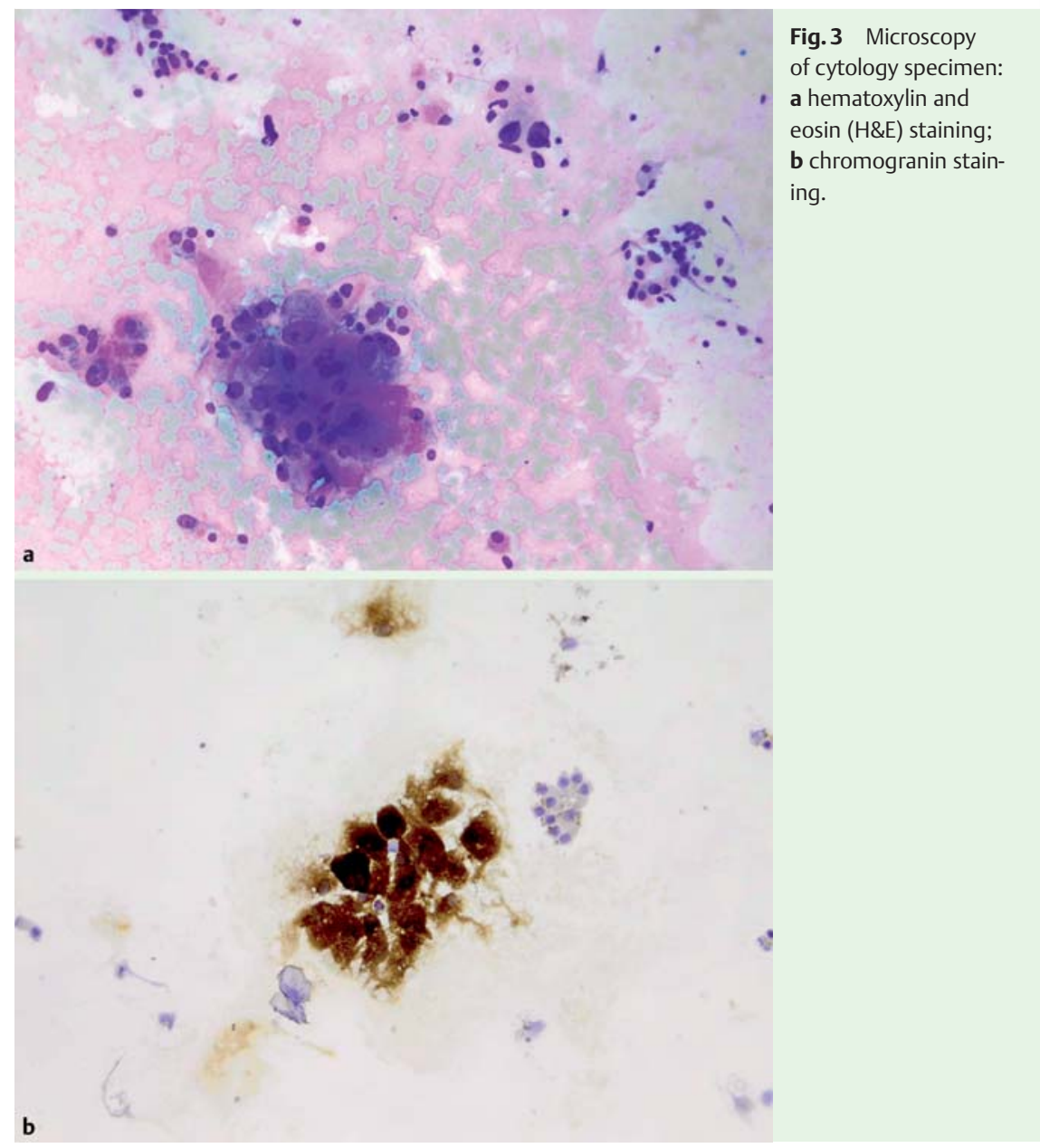

and risk associated with EUS-guided FNA. Gastrointest Endosc 2004; 60: 1018-1021

4 Eloubeidi MA, Eltoum I, Eloubeidi MA. A large single-center experience of EUS-guided FNA of the left and right adrenal glands: diagnostic utility and impact on patient management. Gastrointest Endosc 2010; 71: 745 753

5 DeWitt J, Alsatie M, LeBlanc J et al. Endoscopic ultrasound-guided fine-needle aspiration of left adrenal gland masses. Endoscopy 2007; 39: 65-71

6 Early DS, Acosta RD, Chandrasekhara V. ASGE Standards of Practice Committee et al. Adverse events associated with EUS and EUS with FNA. Gastrointest Endosc 2013; 77: 839-843

7 Sawka AM, Jaeschke R, Singh RJ et al. A comparison of biochemical tests for pheochromocytoma: measurement of fractionated plasma metanephrines compared with the combination of 24-hour urinary metanephrines and catecholamines. J Clin Endocrinol Metab 2003; 88: 553-558

\section{Bibliography}

Dol http://dx.doi.org/

10.1055/s-0034-1377498

Endoscopy 2014; 46: E447-E448

(c) Georg Thieme Verlag KG

Stuttgart · New York

ISSN 0013-726X

\section{Corresponding author}

\section{Annemarie C. de Vries, MD, PhD}

Department of Gastroenterology and Hepatology Erasmus University Medical Center

Rotterdam

The Netherlands

Fax: +31-10-7034682

a.c.devries@erasmusmc.nl 